Bond University

Research Repository

\title{
Risk management processes used in determining project feasibility in the property development process early stages by Australia/New Zealand property developers
}

Moorhead, Matthew; Armitage, Lynne; Skitmore, Martin

Published in:

Journal of Property Investment and Finance

DOI:

10.1108/JPIF-08-2021-0071

Licence:

CC BY-NC

Link to output in Bond University research repository.

Recommended citation(APA):

Moorhead, M., Armitage, L., \& Skitmore, M. (2022). Risk management processes used in determining project feasibility in the property development process early stages by Australia/New Zealand property developers. Journal of Property Investment and Finance, 40(6), 628-642. https://doi.org/10.1108/JPIF-08-2021-0071

\section{General rights}

Copyright and moral rights for the publications made accessible in the public portal are retained by the authors and/or other copyright owners and it is a condition of accessing publications that users recognise and abide by the legal requirements associated with these rights.

For more information, or if you believe that this document breaches copyright, please contact the Bond University research repository coordinator. 


\title{
Risk management processes used in determining project feasibility in the property development process early stages by Australia/New Zealand property developers
}

\begin{abstract}
Purpose. The purpose is to examine the risk management processes and methods used in determining project feasibility in the early stages of the property development process by Australia/New Zealand property developers, including Monte Carlo simulation, Bayesian models and real option theory embedded in long-term property development and investment decision making as instruments for providing flexibility and managing risk, uncertainty and change.
\end{abstract}

Design/methodology/approach. A questionnaire survey of 225 Australian and New Zealand trader developers, development managers, investors, valuers, fund managers and government/charities/other relating to Australia/New Zealand property development companies' decision-making processes in the early stages of the development process prior to site acquisition or project commencement - the methods used and confidence in their organisations' ability to both identify and manage the risks involved.

Findings. Few of the organisations sampled use sophisticated methods; those organisations who are more likely to use such methods for conducting risk analysis include development organisations that undertake large projects, use more risk analysis methods and have more layers in their project approval process. Decision makers have a high level of confidence in their organisation's ability to both identify and manage the risks involved, although this is not mirrored in their actual risk management processes. Although the majority of property developers have a risk management plan, less than half have implemented it, and a third need improvement.

Originality. First study to examine the risk management processes utilised in determining project feasibility by Australia/New Zealand property developers in the pre-acquisition stage of the development process.

Keywords: property development, feasibility analysis, Monte Carlo simulation, sensitivity analysis, scenario analysis, option theory, practical use, survey, Australasia.

Type of paper: academic

Category: research paper

\section{Introduction}

The current risk management practice for real estate companies engaged in property investment, development, redevelopment, rehabilitation and advisory activities is to employ a series of generic hurdle rates based on industry and/or company-specific rules of thumb and industrywide benchmarks commonly expressed as hurdle rates of return (Diaz III, 2010; Havard, 2014; 
Sah et al., 2010). Hurdle rates are used to measure a potential project's viability through conducting a feasibility analysis and inform decision making during the early stages of the undertaking. They designate a minimum level of return or profitability, which is intended to include the developer's cost of capital and a premium commensurate with a subjective assessment of a project's unsystematic risk. This is particularly important in the post-global financial crisis (GFC) property development and property investment industry, where it is critical to understand how the risks, uncertainty and decision process are evolving to ensure a reduced likelihood of project failure given an internal or external shock to the property market.

However, a complicating factor is that not all real estate development activities are short term, with many investors willing to assume early-stage ownership risks to grow value and generate a high return to equity. Longer-term investment-holding periods introduce new risks, uncertainties and change management, which are often unidentifiable at the preliminary feasibility analysis or site acquisition stages of a project. Additionally, the use of discounting methods within heuristic decision models may lead to a bias against longer-term projects in favour of those that return capital in the short term. This is particularly the case with staged developments in many sectors, newly listed assets and infrastructure (Regan, 2015).

A small number of studies have sought to make a thorough survey of the risk management practices used within the development industry. These include Newell and Steglick (2006), Atherton et al. (2008), Costello and Preller (2010), Loizou and French (2012), Wiegelmann (2012), Coleman et al. (2012), Hutchison et al. (2017) and Crosby et al. (2018a and 2018b), and identify new practices that have been developed including the use of Monte Carlo simulation and Bayesian models. However, it is recognised that heuristic rules of thumb based on the decision maker's experience and intuition are prevalent in the industry, and no attempt has been made to measure the effectiveness of heuristic decision making in terms of risk management practices. Wiegelmann (2012) analyses risk management within European development companies but does not fully examine how these models are used in decisionmaking processes. Other studies within Australia are narrowly focussed, surveying only one sector of the industry or one geographical area: Preller (2009), for example, surveys only Queensland residential developers, while Newell and Steglick (2006) sample publicly listed developers. No research as yet examines the extent of the risk management methods used by property developers in the feasibility and pre-commencement stages of the development process.

In response, the aim of this study is to identify the risk management processes used by property development companies in the pre-commitment stages, particularly in the use of Monte Carlo simulations, sensitivity and scenario analysis and real option theory in long-term property development and investment decision making as instruments for providing flexibility and managing risk, uncertainty and change. This involves a questionnaire survey relating to Australia/New Zealand practitioners, specifically to answer the questions: Do they incorporate sophisticated theory-led structured quantitative analysis as part of their project risk analysis in the feasibility models utilised during these early stages of the property development process? Do they use Monte Carlo simulations, sensitivity and/or scenario analysis, Bayesian models and/or real option theory? and Are they confident in their organisation's risk identification and management practices during this stage?

\section{Risk and uncertainty in property development decision making}

Uncertainty is an integral part of the overall development process and also needs to be reflected in the development appraisal (Loizou and French, 2012). As traditional feasibility analysis models in the property development industry focus on a fixed-point method of determining viability, it is necessary to explore how changes to these variables would affect the outcome of 
the project. The methods commonly used to help assess the impact of a change in variables include single variable sensitivity analysis, multiple variable scenario analysis and Monte Carlo simulations (Khumpaisal and Abdulai, 2010).

Sensitivity analysis. That all development appraisal is an act of forecasting cannot be avoided and all forecasts have a degree of uncertainty and error (Byrne, 2002). Often this information is from current prices and sales, extrapolated to the point in time when the cost or income will likely occur (Havard, 2014). While the commonly accepted models give an equal weighting to the importance and impact of different variables and are deterministic in nature (Byrne, 2002), development projects often have a high degree of sensitivity to a small change in key variables as each possesses some degree of uncertainty. The occurrence of a risk event may be measurable and its likelihood very small, but an event can have a major impact on key project hurdle rates (Havard, 2014; Huston, 2015). For instance, property development projects are subjected to inputs with a high level of variance such as rents, yields and \$ per square metre sales, which can have a disproportionate impact on a project's gross realisation (Havard, 2014; Baum et al., 2018). A complete analysis would include a thorough investigation of the level of uncertainty inherent in each of the input variables that are used to determine project viability. These can include income variables, such as market capitalisation rates, net operating income, sales forecasts and cost inputs including financing (Loizou and French, 2012). In practice, the most commonly chosen variables for sensitivity analysis are $\$ / \mathrm{m}^{2}$ sales rates, $\$ / \mathrm{m}^{2}$ rental values, yields, capitalisation rates, construction costs, interest rates and residual land values (Havard, 2014; Miles et al., 2008).

Scenario Analysis. It is generally accepted that there are two types of scenario analysis commonly used in the development industry, comprising simple or basic what-if scenarios and probability-linked scenarios (Mun, 2006). Probability-linked scenario analysis involves assigning a probability of a given scenario occurring (Havard, 2014) to generate an estimate of outcomes that are either optimistic, neutral or pessimistic for the development project (Mun, 2006). A probability-linked scenario can also be used as an additional analysis to add depth to a feasibility analysis or as a method of input variable generation to feedback into the standard appraisal when high levels of uncertainty are present (Byrne, 2002). These probabilities and scenarios are usually subjective, based on the analyst's intuition (Havard, 2014), and Byrne (2002) suggests seeking the opinion of experts to create ranges of expectation for forecasted variables. In addition, as with sensitivity analysis, during the early pre-commencement or acquisition stages, this process involves forecasting to the end of the project - creating further analytical complexity (Thekdi and Lambert, 2012).

Monte Carlo Simulation. The historical use by developers of static single point development appraisal models, when the input variables determining the feasibility of a project are stochastic in nature, can give a false sense of certainty (Atherton et al., 2008) of predicted cash-flows and thereby land value (Glicksman and Greden, 2005). Monte Carlo simulation can provide a useful antidote in allowing more traditional models to be modified to give the developer the ability to quantify the risks involved, and also allow moving from binary best/worst estimates to a range of outcomes and a distribution (Byrne, 1995, 1996; French and Gabrielli, 2004, 2006; Hoesli et al., 2006; Loizou and French, 2012). Historically, however, Monte Carlo simulation has not been readily available in many of the proprietary feasibility analysis software programs and is usually carried out by installing such Excel-based add-ins as Oracle Software's Crystal Ball or Palisade Software's @RISK (Byrne, 2002; Havard, 2014; Atherton et al., 2008).

Real Option Analysis. Williams (1993), Lucius (2001) and Shen and Pretorius' (2013), further development of real option theory applied to property development projects enables the examination of strategies to exercise call options in markets in equilibrium, where the option to commence a development project is treated as the developer holding a call option over the site - the construction/development costs equalling the strike price and the finished building/s 
as the underlying asset (Grenadier, 1996). However, most models proposed are complex and problematic to use in daily practice, with Hutchison et al. (2017) finding property development and investment firms have not adopted this technique in the U.K. for example.

Other empirical studies have examined the risk management attitudes and the risk analysis tools used in the property industry. For instance, Wiegelmann (2012) and Gleibner and Wiegelmann's (2012) survey of European property development firms' risk management processes and attitudes revealed that the use of standardised quantitative risk assessment methods included sensitivity analysis (43.5\%), scenario analysis (43.5\%), Monte Carlo simulations (10.1\%) and the value-at-risk method (7.2\%). Additionally, they typically use a largely intuitive approach to risk assessment and do not necessarily stick to rigid analysis structures, and decision makers view their firm as being slightly risk averse in relation to their competitors. Gehner's (2008) study of a number of Dutch real estate development organisations found that developers knowingly take risks in projects and that the core of their business is making decisions by taking on risks to derive a return. Additionally, this research described a justifiable investment decision as "taking a risk in the context of real estate development is achieved by following a procedural rational decision process, which results in a timely, justifiable and accountable investment decision".

In the U.K., Hutchison et al.'s (2017) survey of U.K. property development and property investment organisations found that few had risk analysis embedded in their decision-making process, although most used some form of sensitivity analysis and many incorporated some form of scenario analysis with a particular focus on downside risk. Only one regularly used Monte Carlo approaches and a few had tried stochastic simulation techniques, which they had subsequently abandoned in favour of more informal techniques. Similarly, "No use of (and little awareness of) real option approaches" in decision making was reported (p. 36). Instead, more reliance is placed on experience and judgement for setting variable parameters in quantitative probabilistic frameworks in project risk analysis, as well as the use of qualitative frameworks and investment committees. Larger organisations were also more likely to have robust risk analysis systems, and smaller firms were more reliant on informal approaches.

In Australia, Preller (2009) surveyed Queensland property development organisations about their decision making in the preliminary stages of the development process, finding that $90 \%$ of the respondents completed sensitivity analysis and some form of risk analysis in their feasibility analysis. Newell and Steglick's (2006) survey of 24 leading property development companies listed on the Australian Stock Exchange (ASX) found that "property developers use a range of sophisticated quantitative and qualitative procedures to assess the various elements of property development risk" (p. 36) - financial feasibility being aided by standardised risk analysis techniques $(100 \%)$, specific financial hurdle rates $(100 \%)$, sensitivity analysis $(87.5 \%)$, DCF models (75\%), probability models (37.5\%) and risk simulations (25\%) (p. 29). Lyons and Skitmore's (2004) survey of project risk management practices in the Queensland engineering and construction industry found property developers to have a high level of risk tolerance, use very high levels of intuition and judgement in risk analysis, high levels of quantitative risk analysis, sensitivity analysis as the predominant method used, with lower levels of usage of Monte Carlo simulation and probability analysis. A similar earlier survey by Uher and Toakley (1999) of the risk management practices in the conceptual phase of commercial development construction projects of 200 Australian construction and development industry stakeholders, found the 37 property developers involved to have a higher level of risk-taking attitudes than the other stakeholders and other studies, although this may be partially attributable to the different time period involved. 


\section{Method}

\subsection{Data collection}

A parallel mixed method design involving a questionnaire survey is used for data collection. The first part is used to obtain consent to participation in the survey and also to verify the respondents' involvement in the decision-making process of selecting and acquiring property development projects. Quantitative questions are immediately followed by qualitative questions - allowing participants to reveal the demographic characteristics of their property development organisation and the decision makers within the organisation, the methods used to determine project viability and assess the risk of a project, and then to immediately reflect or provide reasons in a qualitative open-ended answer. The main purpose of the qualitative questions is to identify where key industry stakeholders and decision makers believe their models can be improved and where they see the decision-making process heading in the future. The survey questions have rating scales, checklists and ranking, as well as open-ended questions to allow participants to provide subjective interpretation. These include questions regarding geography, experience, educational level, job role, organisational structure, developer type (whether trader or investment), property types developed, project size and developer motive. Information is also sought regarding the common risk analysis methods used in practice, including the attributes involved and perceptions of risk tolerance/aversion. The instrument was piloted with 20 industry practitioners and academics working in related fields and their feedback incorporated into the subsequent final version.

The population consists of decision makers within property development companies that conduct development appraisal and feasibility analysis to determine the viability of a potential project as well as the site acquisition in the pre-commitment stages of the development process. Non-random probability sampling methods adopting quota and homogenous sampling methods are adopted. Both homogeneous and purposeful sampling were applied by approaching decision makers within property development companies as a basis of selection to be participants in the survey. The sample population was stratified along the following basis:

- Geographic areas including New Zealand, South-East Queensland, Northern Queensland, Sydney, Melbourne, Adelaide, Canberra, Darwin and Perth

- Residential, commercial, retail, industrial, tourism, aged care, childcare and mixed-use development

- Large, medium-large, medium-small and small developers

- Speculative developer/trader and developer/investor

- Publicly listed and private ownership

- Specialised and diversified developers

The instrumentation of the survey was administered in two different formats from October 2015 to June 2016. The first was an online survey facilitated by the Qualtrics Survey Platform where 187 respondents completed the survey. The second method was a paper form given out at Altus Estate Master training sessions, where 38 respondents completed and submitted the questionnaire. This achieved a sample size of 225 , effectively constituting a $51.5 \%$ response rate.

\subsection{Analysis}

Chi-square tests are used as a preliminary search for statistically significant associations between variables, which are then further investigated with other techniques; the MannWhitney U Test is used to analyse the various grouping of developers against criteria such as hurdle rate selection and use; Decision Trees (DT) are used make predictions of independent 
variables given a dependent variable and also are used to inform which variables should be used in binary and multinomial linear regression; Artificial Neural Network analysis using Multilayer Perceptron is used to determine the key differences between respondent attributes, and specifically in relation to predictors of hurdle rate selection; and Logistic regression (LR) is used to predict the classification of the dependent variable in testing the null hypotheses. See the Appendix for more details All statistically significant results given are at the $5 \%$ level.

\section{Results and discussion}

\subsection{Demographics}

Table 1 summarises the demographics of the 225 respondents, showing a combined $58 \%$ total trader developer and development manager types . Valuation firms were included to gauge their required hurdle rates and risk perceptions in comparison to the property developers whose projects they are analysing. The predominance of private companies is similar to other studies and reflects the generally accepted belief regarding property development organisational structure (e.g., Preller, 2009; Wiegelmann, 2012). The largest classification of property type is residential developers, which is as expected given the majority of buildings constructed in Australia (65.5\% in the year to June 2018) and New Zealand (65.1\% in the year to September 2018) are residential (ABS, 2018b; Statistics New Zealand, 2018). The majority of the respondents conduct development projects in Australia and New Zealand, making a combined $84 \%$ operating in the Antipodean region. Many also operate across several regions with a relatively small percentage of their projects by dollar value being conducted in different areas. A salient feature is that the dispersion distribution for smaller (by transaction volume) markets attract more of a local focus, and the larger, more economically complex, markets demonstrate a more diverse distribution of activity. Prior surveys of property developers in Australia have tended to focus on the larger developers (see Newell and Steglick, 2006, and Preller, 2009). Further analysis (not shown) unsurprisingly demonstrates that larger property development projects are generally taken on by larger property development organisations and smaller property development projects are more likely to undertake smaller development projects.

Table 1. Demographics of the respondents

\begin{tabular}{|l|c|c|}
\hline \multicolumn{1}{|c|}{ Developer profile type } \\
\hline \multicolumn{1}{|c|}{} & No. \\
\hline Trader & & 33 \\
\hline Investor & 18 \\
\hline Dev. manager & 26 \\
\hline Valuation & 8 \\
\hline Fund Manager & 4 \\
\hline Govt/Charity/Other & 11 \\
\hline Total & 100 \\
\hline \multicolumn{2}{|c|}{} \\
\hline Australia & \\
\hline New Zealand & 17 \\
\hline $\begin{array}{l}\text { Other (North/South America. } \\
\text { Oceania) }\end{array}$ & 20 & 9 \\
\hline Did not indicate & 12 \\
\hline Total distribution of projects \\
\hline \multicolumn{2}{|c|}{ Ownership structure of participant organisation } \\
\hline
\end{tabular}




\begin{tabular}{|c|c|c|}
\hline Public traded company (listed) & \multirow{5}{*}{$\begin{array}{c}55 \\
8 \\
117 \\
10 \\
4 \\
\end{array}$} & \multirow{2}{*}{$\begin{array}{c}29 \\
4\end{array}$} \\
\hline Public company (unlisted) & & \\
\hline Private company & & 61 \\
\hline Government & & 5 \\
\hline Other & & 2 \\
\hline Total & 193 & \\
\hline \multicolumn{3}{|c|}{ Type of development projects } \\
\hline Residential majority & 98 & 39 \\
\hline Commercial majority & 16 & 6 \\
\hline Retail majority & 27 & 11 \\
\hline Industrial majority & 27 & 11 \\
\hline Tourism majority & 9 & 4 \\
\hline Mixed-use or No dominant & 53 & 21 \\
\hline $\begin{array}{l}\text { Other, childcare, retirement, } \\
\text { infrastucture }\end{array}$ & 19 & 8 \\
\hline Total & 249 & 100 \\
\hline \multicolumn{3}{|c|}{ Respondent years of experience } \\
\hline $1-2$ years exp & 43 & 23 \\
\hline $2-5$ & 49 & 26 \\
\hline $5-10$ & 43 & 23 \\
\hline Over 10 & 53 & 28 \\
\hline Total & 188 & 100 \\
\hline \multicolumn{3}{|c|}{ Respondent preferred project size (AUD) } \\
\hline $0-10$ million & 25 & 17 \\
\hline $10-50$ million & 23 & 16 \\
\hline 50-100 million & 32 & 22 \\
\hline Over 100 million & 65 & 45 \\
\hline Total & 145 & 100 \\
\hline \multicolumn{3}{|c|}{ Respondent educational background } \\
\hline Highschool or equivalent & 6 & 3 \\
\hline Diploma or trade certificate & 8 & 4 \\
\hline University bachelor degree & 91 & 48 \\
\hline Post graduate diploma & 18 & 10 \\
\hline Master's degree & 61 & 32 \\
\hline Doctorate or professional degree & 4 & 2 \\
\hline Total & 188 & 100 \\
\hline
\end{tabular}

\subsection{Risk appetite perception}

Similar to Wiegelmann's (2012, p. 112) European study, 35\%, 46\% and 19\%, respectively, of respondents perceive their organisation as more risk averse, similar to or more risk-taking than their competitors. Unlike Wiegelmann (2012), however, the t-test reveals no significant difference between private and public structures. This is surprising as it is anticipated that private company structures, which most small development firms would use, would be significantly more risk tolerant, but the survey responses included many development organisations that undertake medium and large projects and also use a private structure. 
However, a one-way ANOVA indicates there are statistically significant differences between those undertaking small, medium and large project sizes, with a Kuznets-like relationship of small being the most risk tolerant, followed by large and then medium: this is in contrast with Whitehead's (1987) result, which has small also being the most risk tolerant, but decreasing steadily with size. The reason may be, as Whitehead (1987) asserts, that small development organisations accept more risk early in order to grow and achieve greater economies of scale, while the risks are larger in size for larger organisations and hence they also appear to be risk tolerant.

The Mann-Whitney U Test reveals a significant difference in the level of risk appetite perception of Trader and other developer types, with the former being risk neutral in comparison to their competitors, which are more risk averse - an unsurprising result, as trader developers fulfil the more speculative aspects of the property development industry, which carries a greater level of risk than other types of developer.

\subsection{Project risk analysis methods}

The most widely used of the common risk analysis methods is the sensitivity analysis of a single variable (45\%): this method is simple to incorporate into the feasibility analysis for a potential development project and has been used within the industry for many decades. The second highest is scenario analysis of multiple variables $(26 \%)$. Qualitative frameworks such as a risk matrix are much less favoured. The Mann-Whitney U test for respondents who use Microsoft Excel indicates only the use of sensitivity analysis of a single variable to be statistically significant with $55 \%$ using this method - their use of other risk analysis methods being negligible. This result is becoming increasingly important, as the rate of development of quantitative risk analysis methods within proprietary feasibility analysis programs has made these tools highly accessible. Such other quantitative techniques as probability analysis $(5 \%)$, Real option theory (4\%) and Monte Carlo simulation (3\%) are much less used - highlighting the continuing substantial disparity between research and industry practice. This is similar to other studies such as Newell and Steglick's (2006) survey of 24 large ASX listed property development companies, finding a $25 \%$ adoption of risk simulation and $37.5 \%$ adoption of probability models - possibly reflecting Marshall and Kennedy's (1993) early conclusion that appraisal techniques suffer more from the input of inaccurate information and lack of objectivity rather than the actual technique used.

The Mann-Whitney $U$ test does not support the commonly accepted notion that larger publicly listed property development companies use more sophisticated highly quantified models because of their access to higher levels of resources including staff. As with Hutchinson et al.'s (2017) U.K. study, there is a very low level of adoption and use of the more sophisticated quantitative techniques including Monte Carlo Simulation, probability analysis, qualitative risk matrix and option theory - all having less than $5 \%$ usage by decision makers, which may be due to the perceived difficulty in applying models to heterogeneous assets, senior management reluctance to accept new approaches and gaps in the knowledge and human capital to incorporate sophisticated modelling techniques (Hutchinson et al., 2017). These explanations may also be relevant to the Australia/New Zealand property development industry and is an area for consideration in future research.

Mann-Whitney U tests also indicate no significant differences between level of use in terms of experience, publicly listed development company and educational levels groups, while ttests of independence indicate a significant difference between groups of those who do and do not use complex quantitative risk analysis methods, the number of approval levels for decision making and the number of risk analysis methods used. 


\subsection{Project risk identification and risk management processes}

It is generally accepted that organisations should aim to identify the key risks of a potential project early in the decision process and assess the impact of these risks on both the project and the organisation as a whole. This step naturally must occur before any active risk management strategies are implemented and form an essential part of the due diligence activities of property development organisations. Most respondents disagree or strongly disagree that it is difficult to identify the main risks for specific projects (77\%), difficult to identify the likelihood of risks occurring (77\%) and difficult to assess the impacts of risks materialising (72\%), while most agree that reliance is needed on external advice in risk identification $(80 \%)$. These are patterned after Wiegelmann (2012, p. 134), but differ in that the focus is on the early stages of the site acquisition and the go/no-go decision process rather than across the complete development process as a whole. This result is also similar to Wiegelmann (2012), concerning European property development organisations. Additionally, Newell and Steglick (2006) found $100 \%$ of respondents, which were ASX publicly listed property developers, had a system of risk identification prior to the commencement of a development project.

When respondents were asked specifically about aspects of their organisation's risk management practices, the overall level of confidence is reduced when expressed in terms of the organisation's management and its attitude to risk identification. Respondents were asked to evaluate the aspects/features of their organisation's project decision-making process and the results are presented in Fig. 1. 
Figure 1: Risk management processes

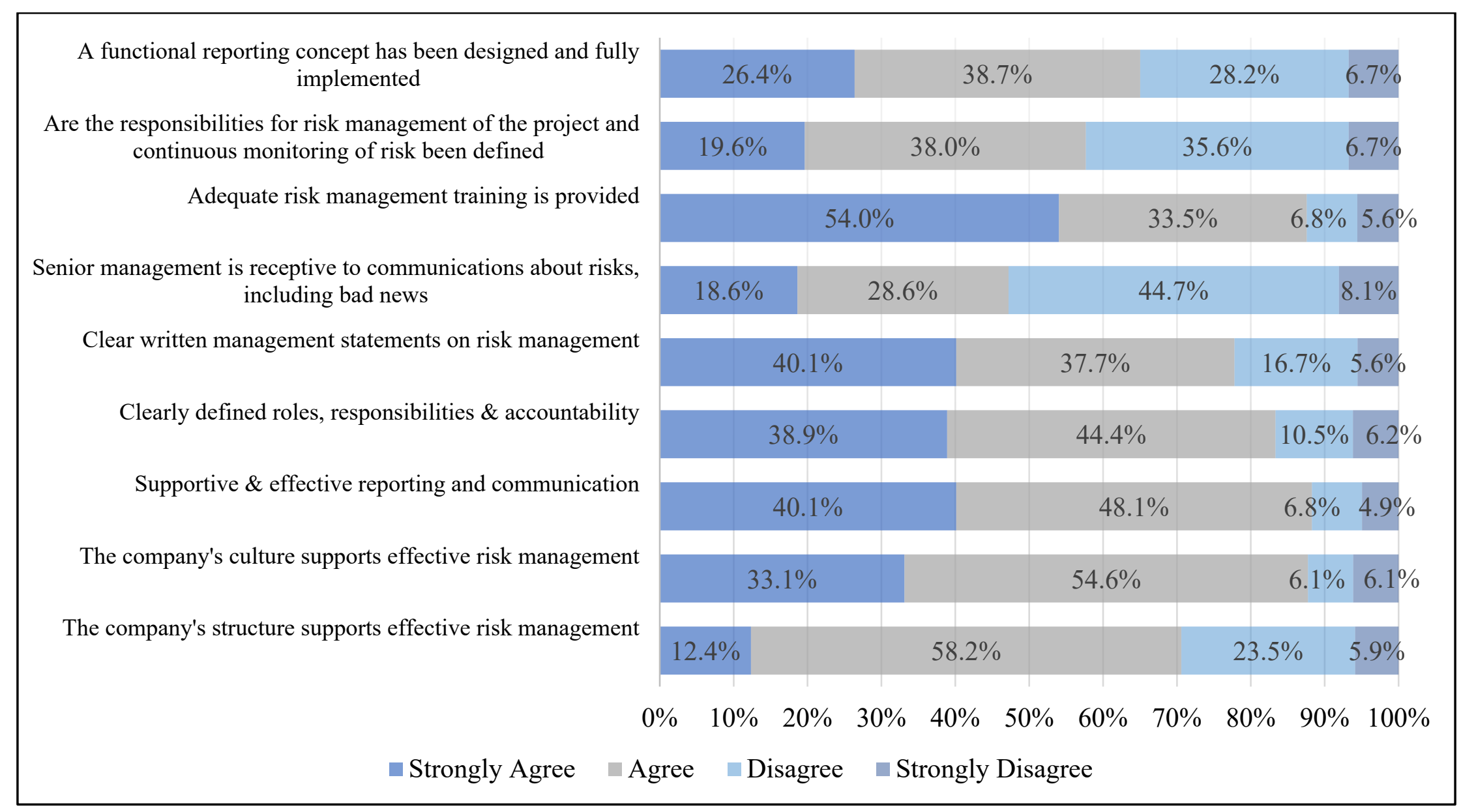


That "the company's senior management is receptive to all communications about risks, including bad news" and "the company's culture supports effective risk management" demonstrate a lower level of confidence indicates that, even though the respondent organisations believe they have systems to adequately identify and manage the risks to their projects, there are cultural aspects that discourage decision makers from actively identifying risks and report them.

There is a high level of confidence in the "provision of risk management training", having "clear and written management statements on risk management", having a "supportive and effective reporting and communication process" and "the company's culture supports effective risk management", which appears to contradict areas with a lower level of confidence. This result is similar to other studies (e.g., Wiegelmann, 2012), however, where a high level of confidence in the organisation's risk management practices is not reinforced by the specific elements of the risk management process.

\subsection{Confidence in risk analysis and management}

In terms of their company identifying and preparing for potentially significant risks in potential projects, $55 \%$ of the respondents have confidence or absolute confidence, with $42 \%$ more or less confident and only $2 \%$ not confident. This result is more optimistic than that found by Wiegelmann (2012), for instance, where the majority of European developers indicated a moderate to a moderately-low level of confidence, though a comparison is difficult as the difference could be attributed to the market conditions facing the property development industry in each region at the time of the survey.

\subsection{Summary of responses to qualitative questions}

The respondents demonstrate a high level of confidence in their organisation's ability to both identify and manage risks that could be encountered by potential property development projects. This is similar to that found by Wiegelmann (2012) but is not supported by the actual risk management processes.

Specific examples of changes to their organisational risk management practices indicate an increased focus on risk analysis, which can be broadly categorised into four themes of "Increased quantitative risk analysis", "Increased [and less prescriptive] qualitative frameworks", "Greater focus on risk awareness (more qualitative)" and "Change in funding arrangements (debt or equity)". Examples given of changes to decision practices with regard to risk identification and management include "Maintaining a live risk register and risk catalogue to allow for organisational risk mitigation and risk transference strategies", "Alternate debt and/or equity strategies including securitisation of equity contributions to projects", "The use of more sophisticated quantitative risk analysis techniques such as Monte Carlo probability simulations and adjusted hurdle and discount rates based on project planning approvals" and "The outcome of a potential project risk analysis".

\section{Conclusions}

This paper examines the risk management processes used by property developers in the acquisition and pre-commencement stages of development projects in long-term property development and investment decision making, including the role of Monte Carlo simulation, sensitivity and scenario analysis, and real option theory in providing flexibility and managing risk, uncertainty and change. The results indicate that few of the Australia/New Zealand property development organisations surveyed use such sophisticated methods, possible continuing to be due to Marshall and Kennedy's (1993) early assertion that appraisal techniques suffer more from the input of inaccurate 
information and lack of objectivity rather than the actual technique used, with those who do being more likely to be a development organisation that undertakes large projects, uses a larger number of risk analysis methods and has more layers in the project approval process. Similar to the findings of previous studies, decision makers have a high level of confidence in their organisation's ability to both identify and manage the risks involved, although this is not supported by their actual risk management processes. The majority of property developers have a risk management plan, with less than half implementing the plan and a third in need of improvement. Half of those with a risk management plan changed it as a result of the GFC.

As demonstrated in prior studies a high level of reliance on intuitive heuristics processes is relied upon by decision makers. A high level of confidence in their risk management and analysis processes was also demonstrated which is not supported by the practical application of more sophisticated methods. Property development organisations should incorporate more modern and sophisticated models of risk analysis in order to determine the uncertainty of, and risk in, a change of input variables in their financial viability appraisals. Practical application would include the use of multiple techniques including what-if scenarios and probability analysis into feasibility processes. In recent times there have been advances in proprietary feasibility analysis programs and Microsoft Excel add-ins that are readily available and which offer the use of Monte-Carlo stochastic simulations and other probability-based quantitative techniques. Property development organisations in Australia/New Zealand should utilise these specific techniques in the preacquisition stages of the property development process and, specifically, in the site acquisition process to support decision-making. In conducting feasibility analysis to determine financial viability in the early stages of the development process, property development organisations should incorporate qualitative risk analysis methods including a live risk register and catalogue of risks, including identification of and plans for mitigation of project risks, as a form of risk management.

This study analysed and presented findings by examining the literature relating to the risk management practices of the industry to provide clear identification of the issues faced by decision makers in the early stages of the development process. Additionally, through the use of an empirical survey and accompanying analysis, these issues were investigated to provide a greater level of clarity of the specific practices used as a basis for determining the viability of potential projects, thereby contributing new perspectives to the body of knowledge.

The study is limited to the demographic characteristics of the respondent organisations, including the types of property developed, types of developers and ownership structure of the respondent organisations, as well as the distinct geographical areas of operation of the participants involved. The survey instrument is limited to the self-reported perceptions, beliefs and experiences of decision makers within property development organisations who primarily conduct projects in Australia/New Zealand, with the survey respondents also self-selecting and required to demonstrate their willingness to participate in the research in the selection criteria questions. It is also limited to a few key variables, whereas a comprehensive investigation of risk analysis in complex development and investment projects would involve many additional variables. Similarly, the investigation of macro- and microeconomic factors, including the impact of severe supply restrictions in property markets within Australia/New Zealand that influence the property and/or real estate market, has been considered only at the secondary level. Further research would benefit from ameliorating such limitations where possible towards developing a universal model or recommendation of the best method for risk analysis. Also needed is a greater understanding of why more sophisticated techniques continue to be generally eschewed by an industry that regards 
itself as the 'risky end' of property investment but does little to analyse that risk as well as providing some comparison with other risk-prone business activity. However, it should also be recognised that heuristic rules of thumb in regards to risk management and decision-making in property development project viability continue to be prevalent and have thus far served the industry well. Nevertheless, the insights obtained in this study into the evolution of the risk management-making processes of successful developers and property investors provide lessons for wider application.

\section{Acknowledgement}

Many thanks go to the anonymous reviewers of the original drafts for their helpful and insightful suggestions, now incorporated into the final version.

\section{References}

Atherton, E., French, N. and Gabrielli, L. (2008), "Decision theory and real estate development: a note on uncertainty", Journal of European Real Estate Research, Vol. 1 No. 2, pp. 162-182.

Barman, B. and Nash, K.E. (2007), "A streamlined real options model for real estate development", Doctoral Dissertation, Massachusetts Institute of Technology.

Baum, A. (2009). Commercial Real Estate Investment. Taylor and Francis.

Baum, A., Devaney, S. and Frodsham, M. (2018), "Yield determination in European office markets: how does pricing respond to bond yields and market activity?" ERES eres2018_76, European Real Estate Society (ERES).

Byrne, P. (2002), Risk, Uncertainty and Decision-making in Property Development. (2 ${ }^{\text {nd }}$ ed.). New York: Routledge.

Coleman, C., Crosby, N., McAllister, P. and Wyatt, P. (2012), "Development appraisal in practice: some evidence from the planning system", Journal of Property Research, Vol. 30 No. 2, pp. 144-165.

Costello, G. and Preller, F. (2010), "Property development principles and process-an industry analysis", Pacific Rim Property Research Journal, Vol. 16 No. 2, pp. 171-189.

Crosby, N., Devaney, S. and Wyatt, P. (2018a), "The implied internal rate of return in conventional residual valuations of development sites", Journal of Property Research, Vol. 35 No. 3, pp. 234-251.

Crosby, N., Devaney, S. and Wyatt, P.(2018b), "Residual land values: measuring performance and investigating viability", in Investment Property Forum (Ed.), IPF Research Programme, London.

Diaz III, J. (2010), "Disrobing beautiful people: an introduction to the special issue of behavioural real estate research", Journal of Property Research, Vol. 27 No. 3, pp. 203-206.

French, N. and Gabrielli, L. (2004), "The uncertainty of valuation", Journal of Property Investment and Finance, Vol. 22 No. 6, pp. 484-500.

French, N. and Gabrielli, L. (2006), "Uncertainty and feasibility studies: an Italian case study", Journal of Property Investment and Finance, Vol. 24 No. 1, pp. 49-67. doi: 10.1108/14635780610700732

Gehner, E. (2008), Knowingly taking risk: investment decision making in real estate development. Eburon Uitgeverij BV.

Gleibner, W. and Wiegelmann, T. (2012), "Quantitative methods for risk management in the real estate development industry", Journal of Property Investment and Finance, Vol. 30 No. 6.

Glicksman, L. and Greden, L. (2005), "A real options model for valuing flexible space”, Journal of Corporate Real Estate, Vol. 7, No. 1, pp. 34-48.

Greenley, D.A., Walsh, R.G. and Young, R.A. (1981), "Option value: empirical evidence from a case study of recreation and water quality”, The Quarterly Journal of Economics, Vol. 96 No. 4, pp. 657673. 
Grenadier, S.R. (1996), "The strategic exercise of options: development cascades and overbuilding in real estate markets", The Journal of Finance, Vol. 51 No. 5, pp. 1653-1679.

Havard, T. (2014), Financial Feasibility Studies for Property Development: Theory and Practice. Routledge.

Hoesli, M., Jani, E., and Bender, A. (2006). "Monte Carlo simulations for real estate valuation", Journal of Property Investment \& Finance, Vol. 24 No. 2, pp. 102-122.

Hutchison, N., Lizieri, C., MacGregor, B., Mansley, N., Portlock, R., Schulz, R. and Zhao, Y. (2017), "An investigation of hurdle rates in the real estate investment process", London: Investment Property Forum. http://www.ipf.org.uk/resourceLibrary/an-investigation-of-hurdle-rates-in-the-real-estateinvestment-process--may-2017--full-report.html

Khumpaisal, S., Ross, A. and Abdulai, R. (2010), “An examination of Thai practitioners' perceptions of risk assessment techniques in real estate development projects", Journal of Retail and Leisure Property, Vol. 9 No. 2, 151-174.

Loizou, P. and French, N. (2012), "Risk and uncertainty in development: a critical evaluation of using the Monte Carlo simulation method as a decision tool in real estate development projects", Journal of Property Investment and Finance, Vol. 30 No. 2, pp. 198-210.

Lucius, D.I. (2001), "Real options in real estate development", Journal of Property Investment \& Finance, Vol. 19 No. 1, pp. 73-78.

Lyons, T. and Skitmore, M. (2004), "Project risk management in the Queensland engineering construction industry: a survey", International Journal of Project Management, Vol. 22 No. 1, pp. 51-61.

Marshall, P. and Kennedy, C. (1993). "Development valuation techniques", Journal of Property Valuation and Investment. Vol. 11 No. 1, pp. 57-66.

Miles, M., Berens, G. and Weiss, M. (2008), Real Estate Development: Principles and Process (4th ed.). Washington, D.C.: Urban Land Institute.

Newell, G. and Steglick, M. (2006), "Assessing the importance of property development risk factors", Pacific Rim Property Research Journal, Vol. 12 No. 1, pp. 22-37.

Preller, F.T. (2009), A critical assessment of pre-construction property development principles and process in Queensland, Australia. (Masters Thesis, Curtin University). https://espace.curtin.edu.au/handle/20.500.11937/1009

Regan, M. (2015), Understanding risk and uncertainty: a brief history. Working Paper WP131, Faculty of Society and Design, Bond University.

Sah, V., Gallimore, P. and Clements, S. (2010), "Experience and real estate investment decision-making: a process-tracing investigation", Journal of Property Research, Vol. 27 No. 3, pp. 207-219.

Shen, J. and Pretorius, F. (2013), "Binomial option pricing models for real estate development", Journal of Property Investment \& Finance, Vol. 31 No. 5, pp. 418-440.

Thekdi, S.A. and Lambert, J.H. (2012), "Decision analysis and risk models for land development affecting infrastructure systems", Risk Analysis: An International Journal, Vol. 32 No. 7, pp. 12531269.

Uher, T.E. and Toakley, A.R. (1999), "Risk management in the conceptual phase of a project", International Journal of Project Management, Vol. 17 No. 3, pp. 161-169.

Whitehead, J. (1987), "Decision making in the property development industry during a business cycle", PhD Dissertation. The University of British Columbia.

Wiegelmann, T.W. (2012), "Risk management in the real estate development industry: investigations into the application of risk management concepts in leading European real estate development organisations",PhD Thesis, ePublications@bond. Bond University, Australia.

\section{Appendix}

The Pearson Chi-square test of independence is 'used when you wish to explore the relationship between two categorical variables' (Pallant, 2011, p 217). Chi-square tests are useful in 
determining if there is a statistically significant association between two variables, but this technique cannot be used as a predictor of a variable. The primary use of Chi-square tests in this study was as a preliminary search for statistically significant associations between variables that were then further investigated with other techniques.

The Mann-Whitney U Test is useful for examining the differences between two independent groups on a continuous measure and is the 'non-parametric alternative to the t-test for independent samples' (Pallant, 2016, p. 227). An advantage of this technique when grouping data by a categorical variable is the examination of median values rather than a mean. This statistical technique was used extensively in this study to analyse the various grouping of developers against criteria such as hurdle rate selection and use. The Kruskal-Wallis Test is the non-parametric alternative to a one-way ANOVA between groups, and also allows for comparison of scores on continuous variables across three or more groups (Pallant, 2011).

Decision Trees (DT) (sometimes referred to as classification trees) are binary trees that split pre-defined categorical data into two groups (Gepp et al., 2012) DT is a stochastic statistical technique that runs repeated iterations of splitting variables into two categories given a set of defined splitting rules. 'DTs offer an easy to interpret and implement non-parametric model that still has the power of a multivariate approach and is able to model interactions between variables' (Gepp et al., 2012, p. 553). A major advantage in the use of DT is that the statistical technique is non-parametric, which removes the requirement of not violating the distribution assumptions. DTs are also able to 'handle missing values and qualitative data, as well as easily be represented in a graphical format' (Kumar et al., 2010). DTs are used within the statistical analysis of this study to make predictions of independent variables given a dependent variable and also are used to inform which variables should be used in binary and multinomial linear regression.

Artificial Neural Networks or ANNs are based on the biological networks that exist within the human brain and were introduced by McCulloch and Pitts (1943). ANNs were later shown to have been a useful technique for testing the relationship between independent variables (Lippmann, 1987; Demyanyk \& Hasan, 2010). ANNs have also been shown as a valuable technique for predicting variables when there are many groups (Lapedes \& Farber, 1987), and also as a predictor of commercial property values (Connellan \& Howard, 1998). ANN analysis using Multilayer Perceptron is used in this study to determine key differences among respondent attributes, and specifically in relation to predictors of hurdle rate selection.

Logistic regression (LR) in both binary and multinomial calculations allows for the use of categorical dependent variables and is often used in literature when dealing with firm decision models (Cybinski, 1995). Additionally, this statistical method is being used more frequently in recent times as it often produces superior results to traditional regression methods when describing the relationship between response variables and one or more explanatory variables (Hosmer et al., 2013). The binary form is used to predict a categorical variable with only two possible outcomes. The multinomial form of LR is used when there are more than two possible outcomes (Anderson et al., 2008). In statistics, logistic regression can be used as a classification method to fit categorical data to a logistic function. "It is used for predicting the outcome of a categorical criterion variable based on one or more predictor (independent or explanatory) variables" (Liu \& Liang, 2014, p. 197). Another advantage of logistic regression is the removal of the requirement of the assumption of normality and linearity within the distribution of independent variables that is present in discriminant based linear regression.

\section{References}


Anderson, D.R., Sweeney, D.J. and Williams, T. A. (2008), Statistics for business and economics. Mason: South-Western College.

Connellan, O. and James, H. (1998), "Estimated realisation price (ERP) by neural networks: forecasting commercial property values", Journal of Property Valuation and Investment, Vol. 16 No., pp. 71-86.

Cybinski, P.J. (1995), "A discrete-valued risk function for modelling financial distress in private Australian companies", Accounting \& Finance, Vol. 35, pp. 17-32.

Demyanyk, Y. and Hasan, I. (2010). "Financial crises and bank failures: A review of prediction methods", Omega, Vol. 38 No. 5, pp. 315-324.

Gepp, A., Wilson, J.H., Kumar, K. and Bhattacharya, S. (2012), "A comparative analysis of decision trees vis-à-vis other computational data mining techniques in automotive insurance fraud detection", Journal of Data Science, Vol. 10 No. 3, pp. 537-561.

Hosmer Jr, D.W., Lemeshow, S. and Sturdivant, R.X. (2013), Applied logistic regression (Vol. 398). John Wiley \& Sons.

Kumar N. (2016), Research Methodology. In: Chronic Regulatory Focus and Financial Decision-Making. Springer Briefs in Finance. Springer, Singapore

Lapedes, A. and Farber, R. (1987), Nonlinear signal processing using neural networks: Prediction and system modelling (No. LA-UR-87-2662; CONF-8706130-4).

Lippmann, R. (1987), “An introduction to computing with neural nets", IEEE ASSP Magazine, Vol. 4 No. 2, pp. 4-22.

Liu, D., Li, T. and Liang, D. (2014), "Incorporating logistic regression to decision-theoretic rough sets for classifications," International Journal of Approximate Reasoning, Vol. 55 No. 1, pp. 197-210.

McCulloch, W.S. and Pitts, W. (1943), "A logical calculus of the ideas immanent in nervous activity", The Bulletin of Mathematical Biophysics, Vol. 5 No. 4, pp.115-133.

Pallant, J. (2011). SPSS Survival manual: A step by step guide to data analysis using SPSS. Crows Nest. New South Wales: Allen \& Unwin.

Pallant, J. (2016). SPSS survival manual: A step by step guide to data analysis using IBM SPSS (6th ed.). Maidenhead, Berkshire, England: McGraw-Hill Education. 